\title{
MULTI-LAYER AGGREGATION IN SMART GRIDS A BUSINESS MODEL APPROACH
}

\author{
Lasse Berntzen, Thomas Brekke and Marius Rohde Johannessen \\ School of Business, University of South-Eastern Norway \\ P.O. Box 235, 3603 Kongsberg, Norway
}

\begin{abstract}
This paper describes a business model innovation approach to multi-layer aggregation in smart power grids. Multi-layer aggregation makes it possible to sell and buy electrical power in the local market. To make this feasible, it is necessary to innovate an efficient business model and technology to handle the transactions between sellers and buyers. The proposed business model will use blockchain and smart contracts to handle transactions between the actors.
\end{abstract}

\section{KEYWORDS}

Smart Grid, Supply-Demand, Solar Energy, Smart Contracts, Blockchain, Disruptive Innovation, Business Model Innovation

\section{INTRODUCTION}

The smart grid describes a power distribution grid with intelligent components that seek to optimize power consumption based on dynamic pricing. Power consumption varies throughout the day, week and year, and the price of electricity is based on supply and demand. When the supply is limited, and the consumption is high the price increases, and in periods with ample supply and low consumption, the price decreases. During the winter, electricity is in demand for heating. During the summer, the demand is lower (and production higher, especially solar energy). Power consumption is higher during days than nights.

The smart grid optimizes energy use by shifting energy use to periods with lower prices. One typical example is the heating of water. A water heater is an insulated container that can keep water warm for several hours. A regular water heater has a thermostat that turns the heating element on when the temperature drops below a threshold. An alternative is to have a lower threshold and turn the heating element on during the night when electricity costs are lower.

The same solution is relevant to refrigerators. They also turn on when the temperature drops below a given threshold. Electric vehicles with batteries may also be charged at times when the price of electricity is lower.

The next section provides an overview of existing research on smart grid business. Section 3 introduces multi-layer aggregation, followed by a section describing blockchain and smart contracts. Section 5 discusses the business model, followed by a section providing conclusions and future work.

\section{EXISTING RESEARCH ON SMART GRID BUSINESS}

Smart grids have been on the research agenda for quite some time, and many researchers have proposed various business models. In this section, we present a brief overview of selected papers.

Shomali and Pinkse (2016) reviewed the disruptive consequences of smart grids (Table 1) for value creation, value delivery, and value capture. They found both enabling and constraining factors affecting existing business models. The authors conclude that for new business models to emerge, we need to see consumer engagement, new players on the supply side as well as strong government intervention. 
Table 1. Impact on the Electricity Firms` Business Model Innovation

\begin{tabular}{|c|c|c|}
\hline & Enabling & Constraining \\
\hline $\begin{array}{l}\text { Value } \\
\text { creation }\end{array}$ & $\begin{array}{ll}- & \text { New value propositions based on renewable energy \& } \\
\text { energy services }\end{array}$ & 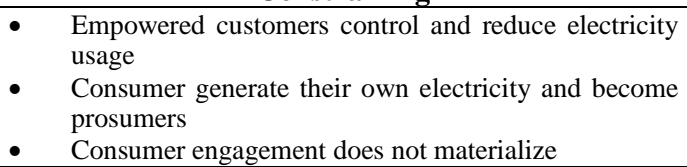 \\
\hline $\begin{array}{l}\text { Value } \\
\text { delivery }\end{array}$ & $\begin{array}{l}\text { - Improved optimization of the electricity network } \\
\text { - Improved marketing based on real-time data on } \\
\text { electricity usage } \\
\text { Leverage assets of specialized ICT or energy service } \\
\text { providers }\end{array}$ & $\begin{array}{l}\text { - The value of conventional power plants erodes } \\
\text { - The risk that new entrants become competitors } \\
\text { Increased complexity of the value network requires } \\
\text { new capabilities }\end{array}$ \\
\hline $\begin{array}{l}\text { Value } \\
\text { capture }\end{array}$ & 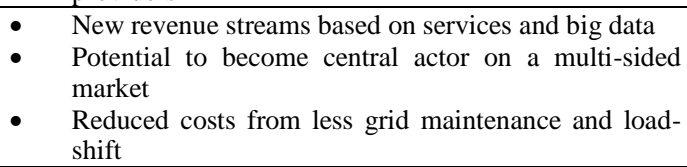 & $\begin{array}{ll}- & \text { Reduced revenues from selling electricity } \\
\text { - Increased costs from investments in smart } \\
\text { infrastructure } \\
\text { Uncertainty about the potential changes in revenues } \\
\text { and costs }\end{array}$ \\
\hline
\end{tabular}

Electric vehicles have a disruptive potential for the power grid, as fast charging of vehicles requires large amounts of power delivered in a short time, putting stress on the grid's capacity. Several different business models have been developed to address this challenge. One example is presented by Budde Christensen, Wells, and Cicigan (2012), who propose a battery leasing scheme, where batteries are owned by a company and customers instead of charging can go to a station and change the battery when needed. This helps alleviate some of the added stress to the grid, as batteries can be charged at times of low demand. The company would be a major purchaser of electricity and could use this purchasing power to negotiate prices and overall lower the cost of running an electric vehicle. The multi-layer aggregation proposed in this paper could further help reduce the running costs.

Giordano and Fulli (2012) also present business models for electric vehicles, as well as for smart homes. They examine the actors involved and the relations between these actors, and their main conclusion is that for smart grid services to succeed, we need system system-level approaches to integrate the different components into a smart ecosystem.

Ubilla et al. (2014) present two different business models for so-called microgrids, which are local energy grids in rural areas with little or no access to the national grid. Using a variety of renewable energy sources, they show how their business model can help with the entire process from financing to implementing and running the local grid. Both models include a local management structure which is in charge of operation and maintenance. The first model has a cooperative structure, made for communities with no dependence on outside actors. The second model is a hybrid structure where the community is still strong, but where there also an added layer of administration hired to handle the operation and management.

Instead of focusing on a particular application area, Rodriguez-Molina et al. (2014) present a review of various prosumer (producer/consumer) business models for smart grids. They identify four different models and present the value-propositions for each. Their conclusion echoes that of Shomali and Pinkse in that they stress the need for active consumers (prosumers) in developing the smart grid: "Prosumers are likely to become the major actor in the development of the smart grid and are no less than the part of the energy market value chain with the greatest potential of business creation based on the services in which they can take part."

\section{MULTI-LAYER AGGREGATION}

New technology makes it possible for households to produce their own energy. Solar power is the leading technology with solar panels installed on roofs, but also geothermal energy may be used. In most cases, the self-produced energy is a substitute for energy consumed from the power grid. The household may also produce surplus energy and sell it back to the grid.

The smart grid contains two key components: The smart meter (Meineche, 2017) that measures the amount of energy transferred between the power distribution grid and the household, and a contract with the distributor establishing payment for energy transferred from the grid to the household and from the household to the grid.

So far, the rates for exporting energy onto the grid has been set by the distribution network operator, operating in a monopoly setting. Even if the rates are based on market price, the price includes the administrative costs of the operator. 
Smart multi-layer aggregation (Smart-MLA) is a concept to loosen up this monopoly and lower the transaction cost by selling energy to a local market. The concept is illustrated in Figure 1. The multi-layer aggregation makes it possible for a household with surplus power to sell its surplus to neighbors instead of putting it on the power grid. If the neighborhood produces surplus energy, the neighborhood can sell its surplus to the next neighborhood instead of putting the surplus onto the grid operated by the distribution network operator. This requires a new business model and technology that reduces administrative costs but also removes the risk of dealing with a network of sellers and buyers instead of one single operator. The technology includes components bridging the local distribution network with the power distribution network. The business model requires an effective and secure revenue stream, in addition to a distributed solution for handling billing between the actors. The bridging components are not discussed in this paper, but we propose to use blockchain and smart contracts to handle the billing process.

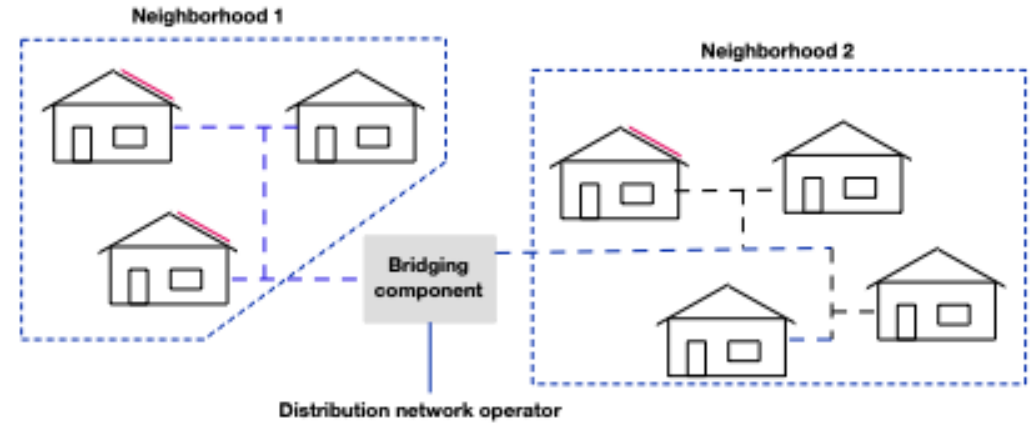

Figure 1. Smart-MLA concept

\section{BLOCKCHAIN AND SMART CONTRACTS}

Blockchain and smart contracts are intimately connected. Blockchain is the enabling technology for smart contracts.

\subsection{Blockchain}

Tapscot and Tapscot (2016) offer the following definition: "Blockchain is an incorruptible digital ledger of economic transactions that can be programmed to record not just financial transactions but virtually everything of value."

Blockchain is an immutable distributed ledger. Cryptographic techniques make sure that it is not possible to change the content of an entry when it is put on the blockchain. All entries are recorded in blocks that are distributed to many computers. If one or more computers fails, the data is still obtainable from the network. If there should be an inconstancy, the majority will win. Essentially, blockchain makes it possible to do transactions without an intermediary.

Themistocleous et al. (2019) discuss how blockchain can be used in the energy sector.

Blockchain may be a possible technology for supporting the business model outlined below. According to Hooper (2018), blockchain has the following features: Increased transparency, enhanced security, improved traceability, increased efficiency and speed, and reduced costs. To maintain the blockchain each transaction will incur a cost. Therefore, the transactions should be aggregated and written to the blockchain at regular intervals, e.g., once every day.

Other authors (e.g., Zheng et al., 2018) have argued that blockchain may not scale well, that it uses too much energy, and that in the future the technology may be replaced by some disruptive innovation discouraging support by platform operators. The risks are discussed below.

Ethereum is an open source blockchain platform with excellent support for writing smart contracts (Mukhopadhyay, 2018). The developer support offered by Ethereum makes the Ethereum platform a viable candidate for the Smart-MLA application. The main reason for using blockchain technology is that multi-layer aggregation involves multiple sellers and buyers without any centralized controlling entity. 


\subsection{Smart Contracts}

A smart contract is a mechanism to store and verify data using self-executable code (Mohanta, Panda and Jena, 2018). The smart contracts run on a blockchain application platform, e.g., Ethereum. Smart contracts are autonomous and distributed. Mukhopadhyay (2018) shows how to write smart contracts that make it possible to store transaction information in the Ethereum blockchain. The smart contracts are written in a dedicated object-oriented programming language: Solidity.

\subsection{Blockchain Risks}

Being aware of the risks associated with blockchains is essential. Today, blockchain is distributed and free. However, there have been some warnings about the scalability and energy consumption to uphold the blockchain. Some future technology may make blockchain obsolete, and at some point, there may be an unwillingness to pay for the computer resources to run the blockchain. In our case the risks are considered low for two reasons:

- The transaction records are only needed for a limited period. The records are needed for fulfilment of payments, and maybe to generate reports for tax purposes.

- The blockchain will have limited size and may be transferred to a private blockchain infrastructure if the public blockchain structure breaks down.

\section{BUSINESS MODEL}

A business model defines how an enterprise creates and delivers value to customers, and then converts payments received to profits (Teece, 2010) in a specific marketplace. In this case, the marketplace is the electrical power market.

The business model handles transactions between sellers and buyers of electric energy in the market. The business model does not only consider customer needs more astutely, but also how to capture values from providing new products and services. According to Teece (2010), a good business model yields value proposition that is compelling to customers, achieves advantageous cost and risk structure, and enables significant value capture by the business that generates and delivers products and services. The value proposition of the smart grid should explain why the actors should prefer this solution compared to other competitive solutions in the marketplace.

\subsection{Fair Price}

The main goal of the new business model is to provide customers with a cost-effective solution for handling trade between themselves. For the consumer, the price should be lower than the market price. For the seller, the price should be above the price offered by the distribution network operator. Figure 2 shows the possible window of pricing. The selling price offered by the distribution network operator will in most cases be above the market price to cover the expenses of the operator. The buying price will normally be lower than the market price, also to cover expenses related to network operation and billing.

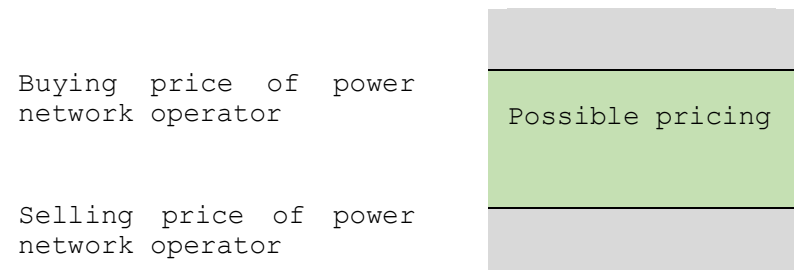

Figure 2. Market window

The costs will be related to smart meters and the bridging components to interconnect the local power grids with the distribution network operators grid. 


\subsection{Value Proposition}

The value proposition of the Smart-MLA solution is to handle transactions between sellers and buyers in a cost-effective way. Electrical energy is dynamically priced, the price is decided on supply and demand. Normally, an intermediary handles the transactions between a seller and a buyer, and the intermediary is paid a commission to handle the transaction. Smart-MLA aims to reduce the transaction costs to a minimum. In practice, the transaction is conducted between the seller and buyer using the Smart-MLA solution for transaction fulfilment. By using blockchain technology, the transaction ledger is stored in the open, and since the blockchain is immutable, the transactions will be safely stored.

\section{CONCLUSIONS AND FUTURE WORK}

Multi-layer aggregation needs entrance of new disruptive smart grid business models that have the capacity to disrupt large energy distributors market monopoly of selling energy to household and propose new value proposition that is compelling to customers, achieves advantageous cost and reduce risk structure. This paper presents one possible business model based on the use of blockchain and smart contracts, and will be used for discussions with stakeholders in the energy business. Workshops for further refinement of the business model are planned and will be conducted during spring 2020.

\section{ACKNOWLEDGEMENT}

The research presented here was funded by The Research Council of Norway as part of the ERA-Net project: Multi-layer aggregator solutions to facilitate optimum demand response and grid flexibility, Project no. 295750.

\section{REFERENCES}

Budde Christensen, T., Wells, P. and Cipcigan, L., 2012. Can innovative business models overcome resistance to electric vehicles? Better Place and battery electric cars in Denmark. In: Energy Policy. 48, 498-505.

Giordano, V. and Fulli, G., 2012. A business case for Smart Grid technologies: A systemic perspective. In: Energy Policy. 40, 252-259.

Hooper, M., 2018. Top five blockchain benefits transforming your industry. Blockchain Pulse: IBM Blockchain Blog, February 22, 2018. [Retrieved May $2^{\text {nd }}, 2019$ ] https://www.ibm.com/blogs/blockchain/2018/02/top-five-blockchainbenefits-transforming-your-industry/

Meinecke, C., 2017. Potentiale und Grenzen von Smart Metering. Springer VS.

Mohanta, B. K., Panda, S. S. and Jena, D., 2018. An Overview of Smart Contract and Use cases in Blockchain Technology. Proceedings $9^{\text {th }}$ International Conference on Computing, Communication and Networking Technologies (ICCNT), IEEE, pp. 1-4.

Mukhopadhyay, M., 2018, Ethereum Smart Contract Development. Packt Publishing Ltd.

Rodríguez-Molina, J., Martínez-Núñez, M., Martínez, J.-F. and Pérez-Aguiar, W., 2014. Business Models in the Smart Grid: Challenges, Opportunities and Proposals for Prosumer Profitability.

Shomali, A. and Pinkse, J., 2016. The consequences of smart grids for the business model of electricity firms. In J. Clean. Prod. 112, 3830-3841.

Tapscott, D. and Tapscott, A., 2016. Blockchain Revolution, Portfolio Penguin.

Teece, D. J., 2010. Business Models, Business Strategy and Innovation. In: Long Range Planning, 43(2-3), 172-194

Themistocleous, M., Stefanou, K., Megapanos, C and Iosef, E., 2019. To Chain or Not to Chain? A Case from Energy Sector. The 15th European, Mediterranean, and Middle Eastern Conference on Information Systems (EMCIS 2018), Lecture Notes in Business Information Processing (LNBIP) 341, Springer, pp. 31-37, ISSN: 1685-1348, ISBN 978-3-030-11394-0.

Ubilla, K., Jiménez-Estévez, G.A., Hernádez, R., Reyes-Chamorro, L., Irigoyen, C.H., Severino, B. and Palma-Behnke, R., 2014. Smart Microgrids as a Solution for Rural Electrification: Ensuring Long-Term Sustainability Through Cadastre and Business Models. In: IEEE Trans. Sustain. Energy. 5, 1310-1318.

Zheng, Z., Xie, S., Dai, H-N, Chen, X. and Wang, H., 2017. Blockchain Challenges and Opportunities: A Survey. International Journal of Web and Grid Services. 14(4):352. 